\title{
Research on Industrial Design Laboratory with Service Design Concept
}

\author{
WANG Qiang ${ }^{1}$, ZHANG Hai-chao², WANG Li $^{2}$ \\ ${ }^{1}$ Dalian Jiaotong University, China \\ ${ }^{2}$ Dalian Institute of Science and Technology China
}

\begin{abstract}
In industrial design teaching, the laboratory is an important teaching space for cultivating students' innovative spirit, practical and creative ability. Laboratory space construction, teaching link design, service and management mechanism directly determine the quality of teaching. The paper explores how to redesign laboratory teaching of industrial design professional through the concept and method of service, which enhances the service experience on the service contact and uses participatory service design tools in the teaching process to improve the teaching process and quality.
\end{abstract}

\section{What is the service design?}

There has not been a clear definition of service design as a professional rise so far, but the attention on user usability, ease of use, and enjoyment is recognized and focused by all, and the focus on service providers has also been paid attention. Therefore, there are obvious differences between service design and interaction design and experience design. Service design is more about system design. Service providers and users participating in the service are audiences. The application of service design is very extensive. A series of teaching activities can be carried out by service design thinking, from teaching system design to performance management. Service design is the design of behavioral systems. The four major elements are stakeholders, contact points, services, and processes. The five principles are user-centered, collaborative innovation, orderliness, tangibility, and integrity.

\section{The background of laboratory construction}

The Internet era of information technology has a certain impact on the whole social structure and relationship. The impact on traditional university education not only brings new knowledge, but also raises new challenge on the organizational form and education methods of university education. new challenge. The paper mainly discusses the study on the redesign of industrial design professional laboratory construction and teaching with the concept and method of service design. For industrial design teaching, face-to-face knowledge transfer can no longer meet the training of talents' innovative practical ability. It breaks the limitation of time and space. Enhancing the interaction between teachers and students can stimulate students' initiative in learning and promote the personalized development of student characteristics. More open laboratory teaching can cultivate students' innovative ability and practical ability.

Service design is a design activity that aims at improving service quality users experience, which plans and organizes the person, things, information communication and other related factors involved in the service so that all the system activities could be reasonable and effective. Service design provides users and servers with reasonable, easy-to-use, satisfied, trustworthy services for the user, which could be both tangible and intangible. Service design is always people-oriented, allowing high-level integration of communication, materials, environment and behavior.

With the development of service design, more and more areas are applying the concept and method of service design, and the education industry has begun to adopt it in various teaching tasks. Many educational experts also realize that the service design thinking is helpful for the laboratory construction and teaching.

\section{The redesign of laboratory space and teaching services}

Try to use the concept and method of service design to design a new learning space, studies the teaching behavior of industrial design laboratory, redesigns the existing space environment to make the use of the laboratory more efficient to adapt to new learning needs.

\subsection{Investigation stage}

The users' experience is not usually generated spontaneously but is guided by the designer. Therefore, the students have expecting experience on laboratory, 
and it must provide them with the appropriate environment and facilities. To understand the students' needs for space and service, research on teaching and research personnel and students to investigate students' needs for laboratory space and services.

\subsection{User portraits}

The portrait of the user is one of the important methods of service design. Through in-depth research on the user, it investigates and analyzes the behavior characteristics and needs of different users and portrays a representative user to represent the motivation of the general user, behaviors and expectations to accurately express the user's core needs.

\subsection{Service route map}

After establishing the persona model, the next step is to use the model to experience the space and services of the laboratory. It combines the role feelings and better design the space of the laboratory by simulating the sequences of users' actions and emotions that the user may have at the service contact point.

When determining the user's portrait, the user can experience the laboratory space and experimental teaching process. Based on the user's feelings, it simulated the actions and emotions of the users generated in the service contact point, and to better design the laboratory space and the experimental teaching process. The road map is only a part of the system behavior design. During the entire design process, it should be considered of different actions, experiences, and feelings in different scenarios of different users. The more different users being analyzed, the laboratory space and teaching process that meet the needs of most users could be designed.

\subsection{Strengthen the coordination and communication of stakeholders}

While applying service design to design education, the students are the ultimate audiences and the most important focus. The student's learning experience is an entirety rather than a single process in the service. Focusing on service learners, students, teachers, knowledge and the environment are the stakeholders of the entire design project, which treats the entire teaching process as an interactive service system. It should concern about students' learning experience and emphasizes the connection and interaction between teachers and students.

It focuses on the openness of space management, emphasizes direct conversations and communication between individuals with fully dialogues. It emphasizes practicing in the form of observations and drills under the guidance of teachers, mixes discussions, rest and cooperation to break the class mode that the teachers teach and students listen to. It encourages students to operate independently in the teaching method that teachers and students discuss together.

\subsection{Enhance the service at contact points}

There exists the problem that limited space with a large number of students for many laboratories in the industrial design profession. During the service design process, all contact points must consider the overall arrangement to create a clear and efficient experience.

In the communication with the lab technicians, it has been discovered that whether it is the mechanical operation of the basic model laboratory or the electronic operation of the rapid prototyping laboratory, the human nerves are in tension, long hours of work and noisy environment can easily affect the human emotions. So, it is very important to design the laboratory environment space so that the teachers and students can have a relaxed and happy attitude in the space.

The overall process of service is the interaction among space, people and their behaviors. Interesting design at the contact points can change the machine's sense of coldness and tension, allowing students who do not have engineering background knowledge to understand the space, notes, reminders, warnings and other information service instructions better.

\subsection{Use participatory service}

The purely experimental hands-on operation is not enough to arouse students' interest, nor can it practically implement practical operations. It can introduce enterprise resources into schools, integrate them into the teaching of the laboratory according to the needs of the enterprises and the company's projects, and stimulate students' autonomy and curiosity. Under the joint guidance of corporate designers and professional teachers, it conducts scientific research training (open experimental projects) and play a role in serving the society with innovation.

\subsection{Change the rhythm of the process to bring new experiences}

It will analyze uniformly all laboratory courses according to the industrial design professional course, make learning service process in the laboratory during the university, which will be dynamically demonstrated in a variety of media so that students can understand the experiment at any time in a variety of channels, to ensure the maximum openness of information.

Based on the conventional teaching process, it selective changes the conventional teaching process, such as the time limit for the transfer of laboratory keys, you can use it before application. 


\section{Enlightenment from Redesign of Laboratory Space and Teaching Services}

\subsection{Develop the diversified functions of the laboratory}

From the process of designing space and services for industrial design laboratories, it has been found that the students' needs for laboratories have greatly changed. The wide spreading of network information technology and mobile devices has also been widely used in the laboratory space. To expand the spatial functions of laboratories, the needs in teaching behavior must be studied to realize the diversification of laboratory spatial functions.

\subsection{Strengthen the social service function of the laboratory}

In more and more teaching behaviors, the exchanges between teachers and students depend on information-based social behaviors. Therefore, it is necessary to add network technologies and various application tools in the laboratory. The rich social functions make teachers and students information acquired and socialization more convenient, not only improves the efficiency of learning, but also stimulates students' imagination.

\subsection{Achieve the self-service of laboratory services}

Simplification is one of the important service principles of the laboratory. Complex procedures can make students shrink back at the sight of using the lab. The important way to simplify services is self-service, which can improve resource utilization and work efficiency.

The self-service reduces the time of communication with management personnel firstly. Secondly, they can operate by individuals in the use process and can independently select what suit their own needs. Thirdly, it also reduces unnecessary waste of time for laboratory workers, who can focus more on more constructive work.

\section{Conclusion}

The rapid development and popularization of social networking and informatization still cannot replace the collective learning, mutual consultation and face-to-face communication between people, especially the entity emotions within a limited space that cannot be replaced by the Internet. So, it is still necessary to continue to research in-depth and create innovative learning spaces that are suitable for learners, and to make full use of the service design theory to continue designing more reasonable and effective emotional perceptions to adapt to the rapid changes in social patterns.

\section{References}

1. LIU Xin, LIU Ji-kun. Possible Opportunity: the Concept and Practice of Product Service System Design (J) . Creation and Design, 5 (2011)

2. LUO Shi-jian, HU Yi . Model Innovation Driven by Service Design [J]. Packaging Engineering, 14 (2015)

3. XU Yue- ren. Research on the Space and Service Design of NCSU Library [J]. Library Forum, 5 (2014)

4. GAO Bo, YIN Zheng-sheng, ZHANG Liang-jun. Design Practice of Service Design Applied to Innovative University Library ( $\mathrm{J}$ ) . Packaging Engineering, 1 (2016)

5. HONG Hua, TAN Xiang-lin, TAO Jin. Analysis of Influencing Factors of Situation Perception on Service Design [J]. Packaging Engineering, 33 (2012) 